\begin{tabular}{c|c|c|}
\hline \hline & CLIMATE RESEARCH \\
Vol. 24: 19-31, 2003 & Clim Res & Published June 10 \\
\hline \hline
\end{tabular}

\title{
Winter severity in the Great Lakes region: a tale of two oscillations
}

\author{
Sergei Rodionov ${ }^{1}$, Raymond A. Assel ${ }^{2, *}$ \\ ${ }^{1}$ Department of Computer Science, Campus Box 430, University of Colorado, Boulder, Colorado 80309-0430, USA \\ ${ }^{2}$ National Oceanic and Atmospheric Administration, Great Lakes Environmental Research Laboratory, Ann Arbor, \\ Michigan 48105-2945, USA
}

\begin{abstract}
The effects of Pacific Decadal Oscillation (PDO) and the El Niño-Southern Oscillation (ENSO) on Laurentian Great Lakes regional winter air temperature and, more generally, surface-air temperatures (SAT) over North America are examined. The relationship between ENSO and winter severity in the Great Lakes is highly nonlinear and depends on the strength of El Niño events. Significant positive correlation between the winter severity and ENSO indices noted in earlier works is limited to strong El Niño events and is associated with an expansion of positive temperature anomalies in NW North America inland toward the Great Lakes. Although both ENSO and PDO are positively correlated with the Pacific-North American (PNA) teleconnection index, a closer look at the large-scale atmospheric circulation associated with the 2 oscillations reveals a substantial difference. During warm PDO phases (not coincident with strong El Niño events), atmospheric circulation resembles the classical PNA pattern, with a strong Aleutian Low at the surface and amplified ridges and troughs in the mid-troposphere. During strong El Niño events the Aleutian Low is also stronger than normal, but shifted eastward, to the Gulf of Alaska. Over North America, an upper atmospheric ridge on the west is not accompanied with a deep trough on the east as in the classical PNA pattern. As a result, outbreaks of cold Arctic air over the eastern US are rare and winters in the Great Lakes region are abnormally mild.
\end{abstract}

KEY WORDS: Great Lakes · Pacific Decadal Oscillation · El Niño-Southern Oscillation Resale or republication not permitted without written consent of the publisher

\section{INTRODUCTION}

The Laurentian Great Lakes of North America are one of the largest single sources of freshwater in the world. They are vital to the economies of both the US and Canada, with over 33 million inhabitants living within their watershed. The lakes are used for commercial and recreational shipping and fishing. Their waters are also used by various manufacturing industries, as municipal water sources and for hydropower generation in their connecting channels (St. Marys River, Niagara River, St. Lawrence River). The severity of winters impacts the regional economy by affecting ice formation on the lakes, waterborne commerce, winter recreational activities, municipal snow removal costs, winter heating costs, and the lake ecosystem
(Assel et al. 1996, Assel et al. 2000). Thus, winter severity, its variation, and factors that influence it are of interest to a large spectrum of people in the private and public sectors of both the US and Canada.

A regional winter severity index (WSI), defined as the temperature for Duluth, MN, Sault Ste. Marie, MI, Detroit, MI, and Buffalo, NY, averaged over November through February, was used in previous studies to identify extremes in winter severity over the past 2 centuries, to model annual maximum ice extent (Assel et al. 1996), and to identify associated atmospheric teleconnections (Rodionov \& Assel 2000). The severity of winters in the Great Lakes region varies greatly from year to year and from decade to decade (Fig. 1a). Warm winters were found to be strongly associated with warm El Niño-Southern Oscillation (ENSO) 
$\begin{array}{lllllllllll}1900 & 1910 & 1920 & 1930 & 1940 & 1950 & 1960 & 1970 & 1980 & 1990 & 2000\end{array}$

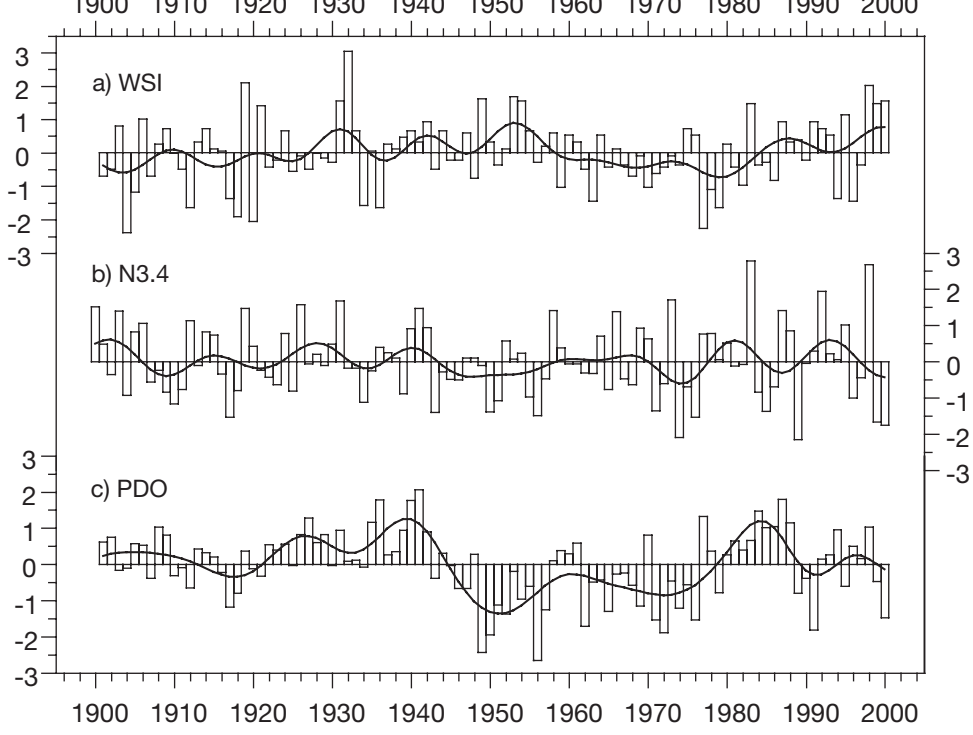

Fig. 1. Standardized anomalies of (a) winter severity index (WSI) in the Great Lakes region, (b) sea surface temperature (SST) in the Niño 3.4 region in the equatorial Pacific (N3.4), and (c) Pacific Decadal Oscillation (PDO). Smoothed lines emphasizing lowfrequency variations were calculated using the Butterworth filter designed to remove periods < 10 yr. Reference period: 1901-2000

events in the equatorial Pacific (Assel 1998, Assel \& Rodionov 1998, Rodionov \& Assel 2000). For example, Assel (1998) has demonstrated that the mean value of the WSI was $1.2^{\circ} \mathrm{C}$ higher (statistically significant at the $5 \%$ level) for the 6 strongest El Niño winters between 1950 and 1994 than its mean value for the other winters in that base period. Assel \& Rodionov (1998) have found that $46 \%$ of the lowest quartile of the observed annual maximum ice covers for the period 1963-1990 occurred during the mature phase of El Niño. The 1983 and 1998 El Niño events both had far-below-average ice cover in the lakes (Assel et al. 2000). Using the multivariate ENSO index (MEI) (Wolter \& Timlin 1993), Rodionov \& Assel (2000) have shown that of 10 winters with strong ENSO events (MEI > 0.8) during the 1950-1998 period, 7 winters in the Great Lakes were warm, 3 were normal, and none were cold.

The association between La Niña events and cold winters in the Great Lakes basin is, however, much weaker and less stable (Assel \& Rodionov 1998). Similar asymmetries (nonlinearities) were noted in a number of recent studies of the ENSO effect on seasonal precipitation, surface temperature, and teleconnection patterns (Zhang et al. 1996, Livezey et al. 1997, Hoerling et al. 1997, 2001, Montroy et al. 1998, Hannachi 2001). For example, Hoerling et al. (1997) have shown that the nonlinear component of the surface-air temperature (SAT) anomalies reaches its maximum over the Great Lakes, making this region particularly inter- esting for studying the mechanism of the ENSO effect on the North American climate.

Although the characteristic signature of ENSO variability lies in the interannual time scale, there is also evidence of notable decadal variability in the equatorial Pacific (Fig. 1b). This decadal variability can be described as either a change in the mean state or a change in the frequency of ENSO events (Graham 1994, Trenberth \& Hurrell 1994, McPhaden 1999). Equatorial temperatures are generally warmer than average after 1976 and are somewhat cooler than average in the $10 \mathrm{yr}$ period prior to 1976. This change is related to the simultaneous change in zonal wind stress on the equator from stronger than normal easterly trade winds prior to 1976 to weaker than normal easterly trade winds after 1976 (Giese \& Carton 1999). It has also been observed that El Niño events have been more frequent and La Niña events less frequent since the late 1970s (Trenberth \& Hurrell 1994).

It is tempting to ascribe a noticeable tendency to warmer than normal winters in the Great Lakes in the last 2 decades to these changes in the tropical Pacific. Recent studies, however, have revealed another oscillation in Pacific seasurface temperature (SST) that can be a likely cause of decadal-scale climatic variations over North America (Latif \& Barnett 1994, Mantua et al. 1997, Zhang et al. 1997). This oscillation, named the Pacific Decadal Oscillation (PDO), exhibits a spatial signature that is similar, in many respects, to that associated with the ENSO cycle. It is often described as a long-lived ElNiño-like pattern of Pacific climate variability (Zhang et al. 1997). Two main characteristics distinguish PDO from ENSO. First, PDO is clearly a North Pacific phenomenon strongly associated with fluctuations in the strength of the wintertime Aleutian Low and with a relatively weak signal in the tropics (Hare \& Mantua 2000). Second, PDO operates on the multidecadal time scale (Fig. 1c) with a characteristic recurrence interval of 50 to $70 \mathrm{yr}$ (Minobe 1997). While observational evidence based on temperature and sea-level pressure (SLP) records is available for just 2 full cycles of the PDO, proxy data such as tree rings suggest that PDOlike climate variability has occurred for more than 3 centuries (Minobe 1997, Biondi et al. 2001). The last transition from a negative (or cold) PDO phase to a positive (or warm) one, which occurred around 1977, manifested itself in a wide range of physical (Miller et al. 1994, Trenberth \& Hurrell 1994, Nakamura et al. 1997, Niebauer 1998) and biological (Venrick et al. 1987, Ebbesmeyer et al. 1991, Mantua et al. 1997) characteristics. This change in the North Pacific climate may be 
another driving force behind the recent warming trend in the Great Lakes region.

Links between the PDO and North American circulation, precipitation, and temperature anomalies are becoming the subject of intense research (Latif \& Barnett 1996, Nigam et al. 1999, Hare \& Mantua 2000, Barlow et al. 2001). Deser \& Blackmon (1995) have linked the SST decadal variability in the North Pacific to the Pacific North American (PNA) atmospheric circulation pattern, which substantially impacts US winter weather (e.g. Leathers et al. 1991). Ting \& Wang (1997) have analyzed coupled variability between US summertime precipitation and Pacific SST variability. While the first coupled mode is associated with ENSO, the second coupled mode exhibits decadal-scale variations and links US summertime precipitation anomalies with SST anomalies in the North Pacific. Barlow et al. (2001) have examined the connection between Pacific Ocean variability and US hydroclimate. In particular, an analysis of upper-level stationary wave activity during the 1962-1966 drought has shown a flux emanating from the North Pacific and propagating over the US. The PDOrelated temperature and precipitation patterns are also expressed in regional snow-pack and streamflow anomalies, especially in western North America (Bitz \& Battisti 1999, Nigam et al. 1999).

The Pacific decadal variability also appears to affect the US wintertime climate through modulation of the ENSO relationship. One point of view on this modulation is that 'canonical' El Niño and La Niña patterns are only valid during years in which ENSO and PDO are in phase. This modulation has been substantiated by Gershunov \& Barnett (1998a) and Gershunov et al. (1999) for North American SLP and precipitation. According to their analyses, El Niño and La Niña signals are strong and stable during so-called 'constructive' ENSO-PDO interference, that is, during warm/warm and cold/cold phases of these 2 oscillations. Alternatively, during 'destructive' combinations (warm/cold and cold/warm) ENSO signals tend to be weak and spatially incoherent and unstable. McCabe \& Dettinger (1999) reached a similar conclusion regarding rainfall over the western half of the US.

An alternative view was recently expressed by Mestas-Nuñez \& Enfield (2001). They have shown that the major patterns of tropospheric variability associated with the ENSO and decadal non-ENSO components (the latter closely resembles the structure of the PDO) are very different. This result contradicts the notion of constructive and destructive interference, in the sense that the climate impacts are likely to be more equivocal and less predictable when the phases of the PDO and ENSO agree because the respective direct circulation anomalies are generally opposite.
In this paper we examine the role of PDO and ENSO in both interannual and decadal variations of winter severity in the Great Lakes and, in a broader context, over North America. First, we show that it is possible to reconcile the 2 seemingly contradictory points of view on the modulation of the ENSO effect by PDO. Next, we explore the nonlinearity of the relationship between ENSO and winter severity and show how this relationship varies depending on the strength of ENSO events. Finally, through partitioning the PDO effect by ENSO, we demonstrate an important difference in the response of large-scale atmospheric circulation over the Pacific/North American sector to these 2 oscillations.

\section{DATA}

Of the various indices used to characterize the nature of ENSO, we have chosen SST anomalies in the Niño 3.4 region $\left(5^{\circ} \mathrm{N}-5^{\circ} \mathrm{S}, 120-170^{\circ} \mathrm{W}\right)$. SST anomalies in this region are well known to exert a strong influence on extratropical circulation during boreal winter (Graham \& Barnett 1995). Normalized monthly values of these anomalies (Trenberth \& Stepaniak 2001) were used to calculate the winter (DJF) index, hereafter referred to as N3.4 index (Fig. 1b). Gershunov \& Barnett (1998a) used a similar index in their study of an interdecadal modulation of ENSO influence on SLP and precipitation over North America.

The PDO index is defined as the leading principal component of North Pacific monthly SST variability, poleward of $20^{\circ} \mathrm{N}$ (Mantua et al. 1997). When SSTs are anomalously cold in the interior North Pacific and warm along the North American coast, the PDO indices have positive values. When the SST anomaly pattern is reversed, with warm waters in the interior and cold waters along the coast, the index values are negative. In parallel with the ENSO phenomenon, positive and negative phases of the PDO are also called warm and cold phases respectively.

PNA index values for the period 1950 to present are available from the Climate Prediction Center (NCEP/ NOAA). Yin (1994) reconstructed this index back to 1895 using a regression model linking the index with surface temperature anomaly field across the continental US. The model explains $89 \%$ of the variance in the observed Pacific-North American (PNA) index during the 1948-1988 period used for model fitting and offers unbiased estimates.

To calculate the correlation fields we used NCEP/ NCAR reanalysis data (Kalnay et al. 1996) and a merged SAT/SST dataset representing a combination of land air temperature anomalies (Jones 1994) and SST anomalies (Parker et al. 1995) on a $5^{\circ} \times 5^{\circ}$ grid-box 
basis. The merging of the 2 datasets is discussed in Parker et al. (1994). The dataset has been extensively used in various reports of the Intergovernmental Panel on Climate Change (e.g. Nicholls et al. 1996).

\section{ENSO EFFECT}

Many researchers have documented ENSO signals in the North American temperature (Ropelewski \& Halpert 1986, Kiladis \& Diaz 1989, Halpert \& Ropelewski 1992, Gershunov \& Barnett 1998b). Fig. 2a shows a distribution of the correlation coefficients between the N3.4 index and SAT over North America for the period 1901-2000. It illustrates a well-known tendency for SAT anomalies during El Niño events to be above normal along the west coast of North America, western and central Canada, and below normal in the southern tier US and the Gulf of Mexico. This distribution of SAT anomalies is often explained through the PNA type of atmospheric circulation excited during El Niño events (Halpert \& Ropelewski 1992). In fact, the N3.4-SAT (Fig. 2a) and PNA-SAT (Fig. 2b) correlation patterns have much in common. This similarity is characterized by a spatial correlation coefficient between the 2 patterns of $r=0.80$.

There are, however, some differences between the 2 patterns, and one of the most noticeable is the extent of the area of positive correlation inland. In Fig. 2b, the Great Lakes are positioned right in between the positive and negative correlation centers, suggesting no impact of the PNA pattern on winter severity in this region. In contrast, the area of positive correlation in Fig. 2a extends much farther eastward, reaching the Great Lakes. The correlation coefficient between the N3.4 index and WSI is relatively low $(r=0.25)$, but still statistically significant at the $95 \%$ level. From a purely statistical point of view, the difference between the correlation patterns in Fig. 2a and b may well be within sampling variability. Nevertheless, as it will be shown below, the difference makes physical sense and is associated with a shallower climatological trough over eastern North America during strong El Niño events.

A comparison of Fig. 2a with similar correlation (or composite) maps published by different authors to characterize the ENSO effect on North American SAT anomalies reveals a substantial difference between the maps ${ }_{1}{ }^{1}$ particularly regarding the degree of expansion of the northwestern center of positive correlation

\footnotetext{
${ }^{1}$ This comparison was made on a qualitative level. Our experience of working with similar data suggests that the difference between the maps may exceed the sampling variability, but due to technical difficulties, a formal statistical analysis was not conducted
}

inland. In some works (e.g. Ropelewski \& Halpert 1986), positive SAT anomalies quickly decrease, and the correlation coefficients become insignificant as one moves toward the central parts of the continent. Bunkers et al. (1996) found no significant ENSOrelated winter temperature response in the Northern

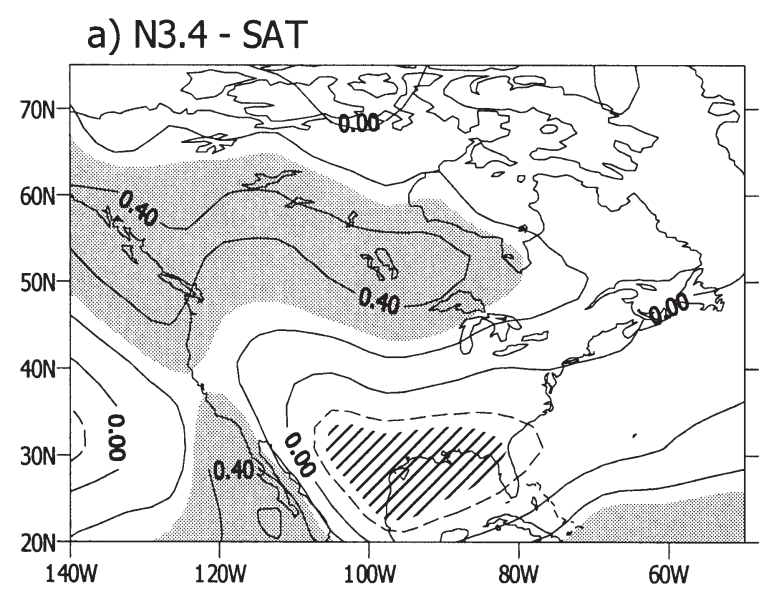

b) PNA - SAT
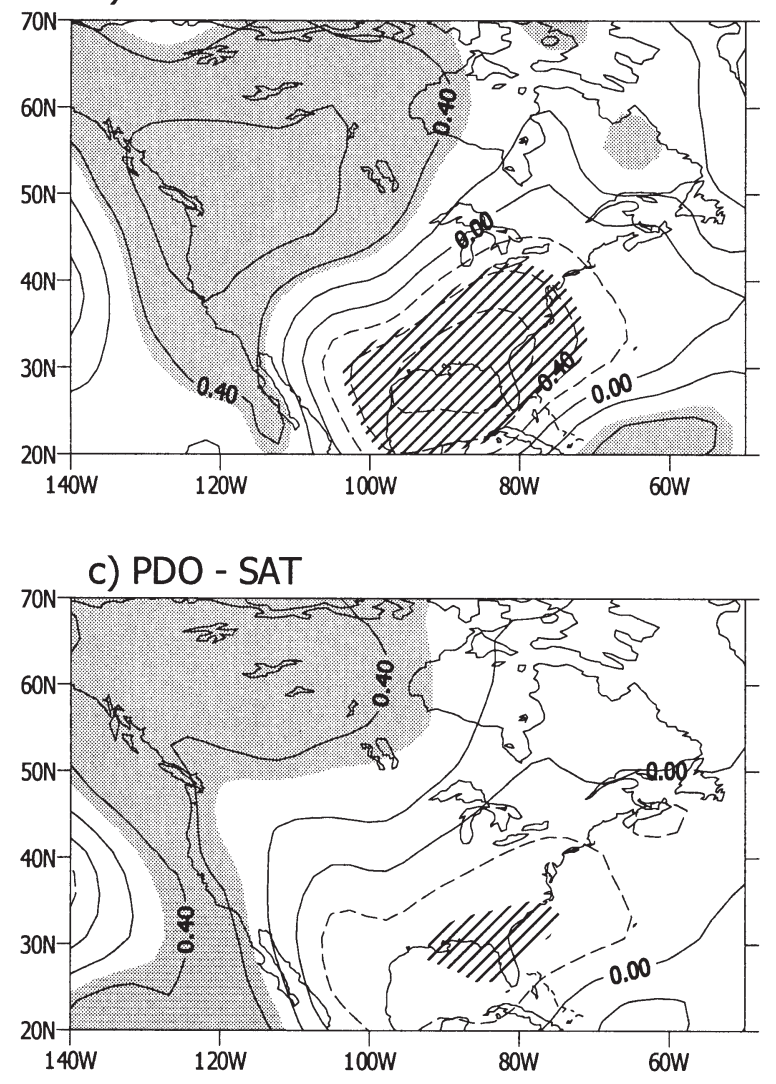

Fig. 2. Correlation of surface-air temperatures (SAT) in grid points over North America with 3 indices: (a) N3.4, (b) PNA (Pacific-North America), and (c) PDO. Stippled and hatched areas: correlation coefficients are locally significant at the $95 \%$ level. Contour interval: 0.2 


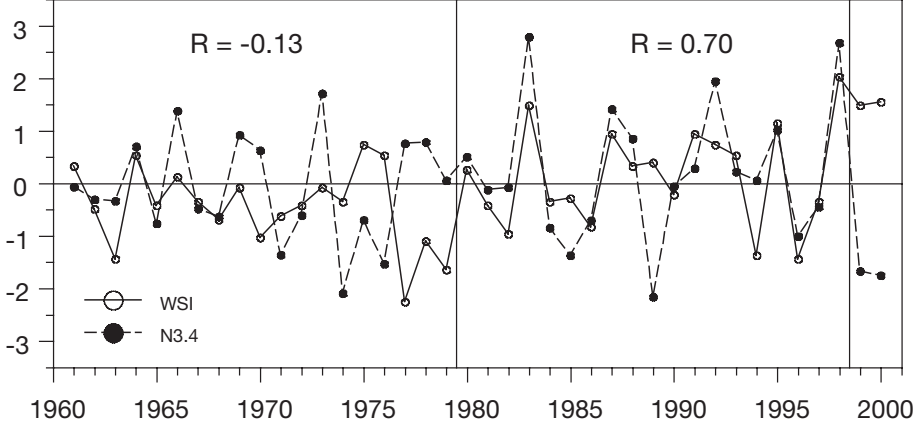

Fig. 3. WSI (solid line) and the N3.4 index (broken line), 1961-2000. Note the difference in the correlation coefficient between the 2 indices for 1961-1979 and 1980-1998

Plains, which did not surprise them because this region is on the periphery of the northwestern SAT anomaly. In more recent works that include data for the past decade or two (e.g. Shabbar \& Khandekar 1996, Gershunov \& Barnett 1998b), the emphasis is on the central parts of North America, where SAT anomalies are even more profound than in the northwest.

This substantial variability in the configuration and inland expansion of the northwestern temperature anomaly is the reason for significant temporal variations in the correlation coefficient between the N3.4 index and WSI, as illustrated in Fig. 3. During the 1961-1979 period the correlation coefficient between the 2 indices is $r=-0.13$, suggesting no relationship at all. During the next 19 yr period, 1980-1999, which was characterized by stronger and more frequent El Niño events (Trenberth \& Hurrell 1994), the correlation coefficient jumped to $r=0.70$. To test the significance of the difference between the 2 correlation coefficients, we calculated a $z$-score using Fisher's r-to- $z$ transformation (Cohen \& Cohen 1983). The $z$-score in our case is 2.82 , which is associated with a p-value of 0.005 (2-tail test). Therefore the 2 correlation coefficients are indeed statistically different.

As noted by Hoerling et al. (1997), the ENSO effect on the Great Lakes is highly nonlinear. To demonstrate this we calculated correlation coefficients between the N3.4 index and WSI for different ranges of the former. To do so we ranked the years according to their N3.4 index, then for each year, we took a group of 21 yr consisting of that year plus the next 10 lower and next 10 higher on this list. The correlation coefficients for each of these 21 yr groups were referred to the median values of the N3.4 index in the groups. The correlation function calculated this way is presented in Fig. 4a along with the $95 \%$ significance level calculated using the $t$-test for individual $21 \mathrm{yr}$ samples. As seen, the correlation between the N3.4 index and WSI varies sub- stantially depending on the range of the N3.4 index, to the extent that it even changes its sign. We also calculated in the similar manner the N3.4-PNA (Fig. 4b) and WSI-PDO (Fig. 4c) correlations as a function of the N3.4 index.

At this point the question arises of whether Fig. 4 represents just sampling variability of these correlation coefficients. Considering a similar problem, Gershunov et al. (2001) calculated a table that allows one to evaluate how significant the standard deviation of running correlation coefficients is for 2 observed time series compared with that for 2 randomly generated (but correlated!) time series. The standard deviations of the running correlation coefficients in Fig. 4 are $0.27,0.24$, and 0.26 for the WSI-N3.4, N3.4-PNA, and WSI-PDO correlations respectively. These numbers are about the same as in Table 1a (95 percentile) from Gershunov et al. (2001) for a 21 yr window width and population correlation coefficients from 0.2 to 0.5 . From this we can conclude that the variability of the correlation coefficients in Fig. 4 is significant at a level of approximately $95 \%$.

A comparison of Fig. 4a and b suggests that the effect of El Niño events on North American temperature may be different depending on the strength of the event. Fig. $4 \mathrm{~b}$ shows that only for a range of moderate El Niño events $(0.45<$ N3.4 < 1.10) does the correlation

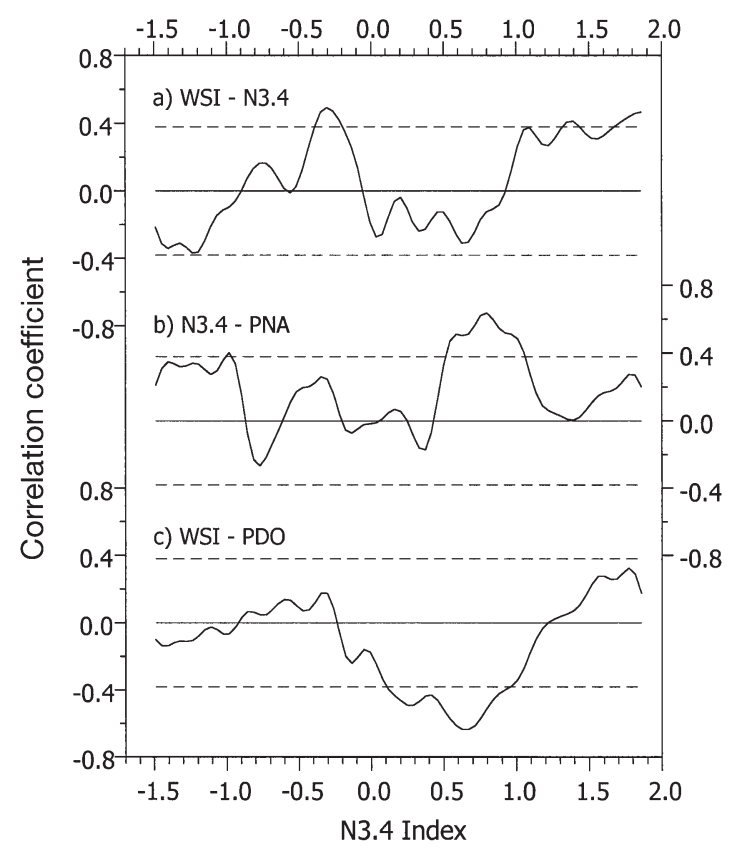

Fig. 4. Correlation coefficients for (a) WSI-N3.4, (b) N3.4PNA, and (c) WSI-PDO as a function of the N3.4 index (see text for details). Broken lines: $95 \%$ significance level 


\section{a) Strong El Niño events}

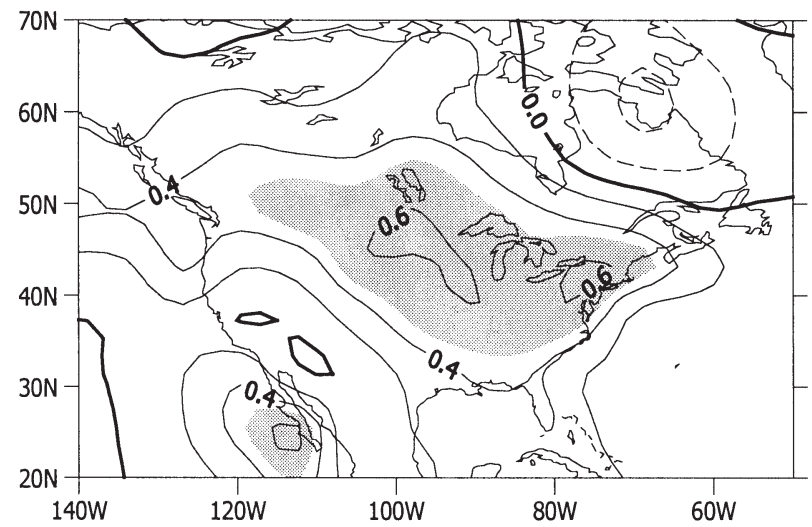

b) Moderate El Niño events

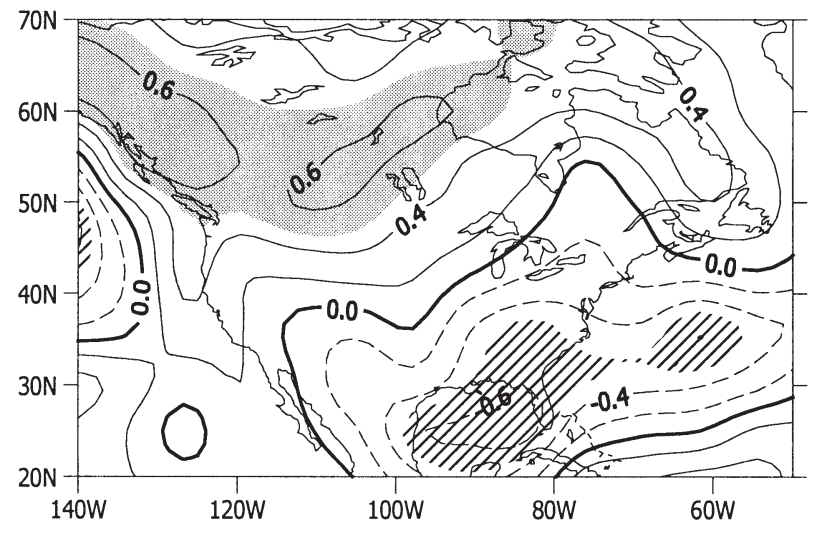

Fig. 5. Correlation of SAT in grid points over North America with the N3.4 index for (a) strong (N3.4 > 1.10) and (b) moderate $(0.45<\mathrm{N} 3.4<1.10)$ El Niño events. Stippled and hatched areas: correlation coefficients are locally significant at the $95 \%$ level

between the N3.4 and PNA exceed the 95\% significance level. At the same time, these events have little impact on winter severity in the Great Lakes (Fig. 4a), which is consistent with the PNA temperature pattern (Fig. 2b). For strong El Niño events (N3.4=1.10), the N3.4-PNA correlation becomes insignificant, while the N3.4-WSI correlation reaches the significance level.

The difference in the response of North American temperature to strong and moderate El Niño events is clearly seen in Fig. 5. During strong El Niño events (Fig. 5a) the correlation coefficients are highest in the northern US, from the Great Plains to the East Coast. The stronger the El Niño, the warmer it is in this area. The El Niño events of 1983 and 1998-the strongest events of the 20th century - are good examples of this type of SAT anomaly pattern in North America. Assel et al. (2000) found that these 2 El Niño events were major factors in producing extremely warm winters in the Great Lakes. Annual maximum ice cover in winter
1998 was at its lowest value since records were started in 1963 on Lakes Erie, Huron, Ontario, and Superior and near its record low on Lake Michigan. Winter 1983 also had anomalously low annual maximum ice extent similar to winter 1998. The distribution of the correlation coefficients during moderate El Niño events (Fig. 5b) resembles the PNA type (Fig. 2b) with the zero isoline crossing the Great Lakes.

An important question is whether the strength of the N3.4-WSI correlation varies depending on the phase of the PDO. To answer this question, we calculated the correlation coefficients between these 2 indices for different gradations of the PDO index in the same manner as we did for Fig. 4. As seen in Fig. 6, the correlation between the N3.4 index and WSI is close to zero for strongly negative values of the PDO index and becomes significant at the $95 \%$ level for positive values of the index. To check whether this variation in the correlation coefficient is statistically significant or just a sampling variability of the overall correlation coefficient of 0.25 between these 2 indices, we calculated the standard deviation of the running correlation coefficients, which in this case was 0.22 . The corresponding number from Table 1 in Gershunov et al. (2001) is 0.27, which did not allow us to reject the null hypothesis that the variability of the correlation coefficient is simply noise. Still, the almost monotonous increase in the strength of the correlation with the values of the PDO (Fig. 6) did not appear to be completely random and required further examination. Therefore we repeated the analysis of Gershunov et al. (2001), but instead of the standard deviation we calculated the autocorrelation at lag 1 (r1), which characterizes the strength of a trend in the running cross-correlation coefficients. Given the 0.25 population correlation coefficient between 2 randomly generated time series and $21 \mathrm{yr}$ running window, the 95th percentile for $\mathrm{r} 1$ turned out to be 0.96 , which was equal to $\mathrm{r} 1$ for the observed time series of the N3.4 and WSI. It means that the observed behavior of the running cross-correlation coefficients between these 2 indices is likely to be more than just noise.

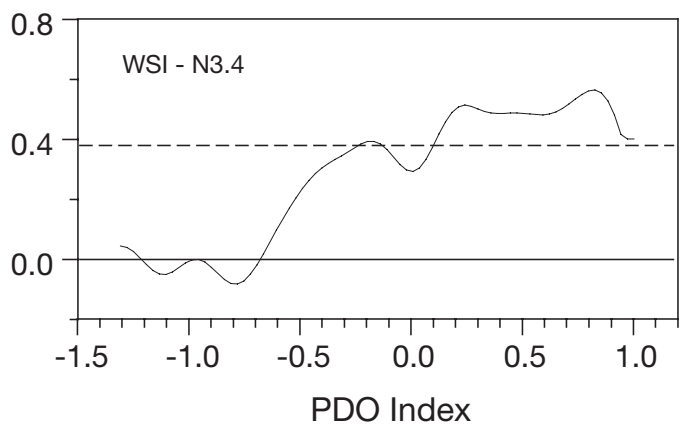

Fig. 6. Correlation coefficient between the WSI and N3.4 index as a function of the PDO index 
We also calculated correlation coefficients between the N3.4 index and WSI separately for negative $(\mathrm{r}=$ $0.08 ; 48$ pairs of data) and positive $(r=0.41 ; 52$ pairs of data) values of the PDO index and tested the null hypothesis that the two are statistically indistinguishable. The test based on the $z$-score (Cohen \& Cohen 1983) showed that this null hypothesis can be rejected at $\mathrm{p}=0.07$. In other words, the PDO appears to modulate the ENSO effect on winter severity in the Great Lakes region.

A possible interpretation of this modulation is that warm phases of the PDO enhance the effect of ENSO on winter severity in the Great Lakes by increasing the probability of strong El Niño events. In fact, out of the 10 strongest El Niño events, ${ }^{2}$ only 1 (1973) occurred during a cold PDO phase. If we call the temperature pattern in Fig. 5a a 'canonical' response (rather than that in Fig. 5b), then our results are consistent with the findings of Gershunov \& Barnett (1998a) regarding the 'constructive' and 'destructive' ENSO-PDO interferences.

\section{PDO EFFECT}

The importance of SST anomalies in the North Pacific as a source of climate variability over North America was highlighted in the pioneering works of Jerome Namias (1959, 1963, 1969, 1978). He emphasized that persistent extratropical SST anomaly patterns are often associated with persistent atmospheric teleconnection patterns. He paid particular attention to a region in the east-central North Pacific, centered near $35^{\circ} \mathrm{N}, 165^{\circ} \mathrm{W}$. Cold waters in this region are generally associated with warm waters along the west North American coast. A typical atmospheric response to this distribution of SST anomalies (which corresponds to a warm PDO phase) consists of an upper atmospheric ridge over the western US and a trough over the eastern US. Alternatively, when waters in the east-central North Pacific are warm (which corresponds to a cold PDO phase), the climatological ridge-trough system over North America is damped or there is a trough over the western US and a ridge over the eastern US (Namias et al. 1988). In a more recent study, Wallace \& Jiang (1987) found that SST anomalies at $35^{\circ} \mathrm{N}$, $165^{\circ} \mathrm{W}$ are more important for specifying wintertime $500 \mathrm{hPa}$ height over the North American sector than equatorial Pacific SST anomalies.

\footnotetext{
${ }^{2}$ These El Niño events (in order from highest to lowest N3.4 index) are 1983, 1998, 1992, 1973, 1931, 1926, 1919, 1941, 1987, and 1958
}

An excellent analysis of large-scale ocean-atmosphere interaction in the North Pacific was provided by Namias (1978) in his search for the causes of the severe North American winter of 1977, when extreme cold dominated the eastern US. This winter of a moderate El Niño event marked the beginning of a new multidecadal regime of warm PDO phase. A persistently strong Aleutian Low (which, following Bjerknes' [1969] hypothesis, was associated with the El Niño event) generated a pool of anomalously cold waters in the eastcentral North Pacific. These cold waters were accompanied by warm waters along the North American coast. The atmospheric baroclinicity from the strong seasurface gradient near $140^{\circ} \mathrm{W}$ strengthened fronts and cyclones. The gradient increased the upper-level southerly flow and steered storms far north of their usual path. Vorticity redistribution from this wind system reinforced the West Coast ridge and the Eastern trough, with recurrent outbreaks of Arctic air to the eastern US. The PNA index during the winter of 1977 was the highest during the entire period of its direct calculations (1949-2000) and for the reconstructed data since 1895 (Yin 1994).

As shown in Fig. 2C, a typical response of North American winter temperature to PDO resembles the PNA pattern (Fig. 2b). The spatial correlation coefficient between the distributions in Fig. $2 \mathrm{~b}$ and $\mathrm{c}$ is $\mathrm{r}=$ 0.86 , which is even slightly higher that that between Fig. $2 \mathrm{a}$ and $\mathrm{b}(\mathrm{r}=0.80)$.

Since the ENSO effect on North American temperature is nonlinear, it was interesting to determine whether there is a difference in the correlation patterns for warm and cold PDO phases. These patterns (not shown) turned out to be similar to each other and to the overall pattern in Fig. 2c in terms of geographic position of the correlation centers. The absolute values of the correlation coefficients, however, are higher for the cold phase than for the warm phase. This is consistent with the result of Barlow et al. (2001) for precipitation. They found that, although the strength of the PDO-precipitation relationship varies from warm phase to cold phase, the overall patterns remain similar, maintaining the same centers of action.

Fig. 4c shows how the PDO-WSI correlation changes depending on the N3.4 index. While the overall correlation coefficient between these 2 indices is close to zero, for the range of weak and moderate El Niño events, it becomes significant at the $95 \%$ level, reaching the value of -0.64 . As shown in the next section, both the PDO and moderate El Niño events tend to amplify the ridge-trough system over North America so that an advection of cold Arctic air to the Great Lakes region increases. Therefore, when the two act together, the weather in the Great Lakes can be really cold, as happened during the winter of 1977. 


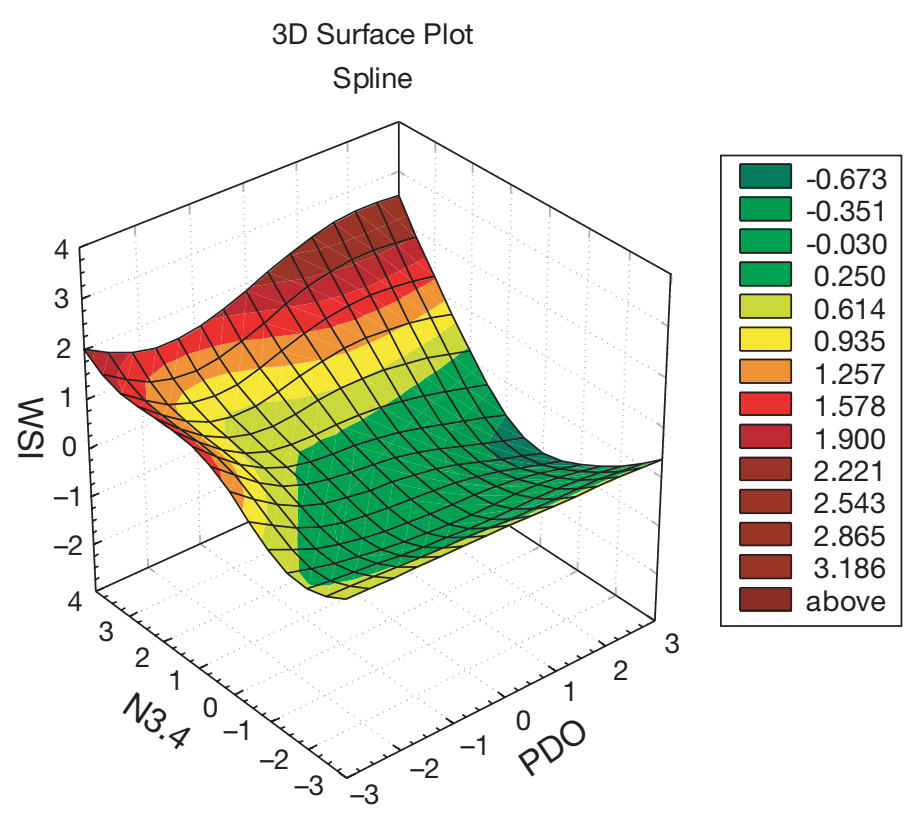

Fig. 7. 3D surface plot of the WSI as a function of the N3.4 and PDO indices smoothed by a cubic spline

\section{SIMILARITIES AND DIFFERENCES BETWEEN ENSO AND PDO}

Let us now emphasize the similarities and differences between the 2 oscillations that will help us better understand their combined effect on North American temperature. As noted earlier, the spatial patterns of ocean-wide Pacific SST anomalies associated with ENSO and PDO are very similar. In addition, the reaction of large-scale atmospheric circulation to these oscillations also appears to be similar. It has long been known (Bjerknes 1969, Angell \& Korshover 1984) that the Aleutian Low tends to intensify during El Niño events. Alternatively, during La Niña events the Aleutian Low weakens and often splits into 2 centers: one in the northwest Pacific and one in the Gulf of Alaska (Niebauer 1998). Renwick \& Wallace (1996) found that the occurrence of blocking in the Bering Strait region is sensitive to the polarity of the PNA pattern, but it is even more sensitive to the phase of the ENSO cycle. In total, $69 \%$ more days of blocking are observed during La Niña winters, compared with those occurring during El Niño winters.

Likewise, the PDO is closely linked with SLP fluctuations in the Aleutian Low, with low (high) SLP corresponding to the warm (cold) phase of PDO (Mantua et al. 1997). Bond \& Harrison (2000) examined how the state of PDO affects the atmospheric flow (troughs and ridges) over the central Pacific. They found troughs (ridges) are favored during warm (cold) phases of PDO slightly in terms of duration and strongly in terms of frequency.
During warm ENSO events in the tropical Pacific the PNA index has a tendency to be positive, and negative during cold events (Horel \& Wallace 1981, Hamilton 1988, Renwick \& Wallace 1996, Renshaw et al. 1998). The Aleutian Low is also highly correlated with variability in the PNA teleconnection pattern (Trenberth \& Hurrell 1994). It is not surprising, therefore, that when all the data are pulled together the North American winter temperature exhibits a similar PNA-like response to both ENSO and PDO (Fig. 2). This response represents a dipole pattern with the Great Lakes region being in between the 2 anomalies. Due to its position, this region does not experience much of the effects of the 2 oscillations, when they are expressed in the form of overall correlation patterns with no partitioning, that is, in a linear manner. The Great Lakes, however, are positioned to pick up the nonlinear effects, the analysis of which allows us to suggest that the physical mechanisms through which ENSO and PDO operate on North American temperature are principally different.

Fig. 7 shows a 3D surface plot that illustrates the nonlinearity of the combined effect of ENSO and PDO on winter severity in the Great Lakes region. As seen, the winters in the Great Lakes are getting milder as the N3.4 index increases. The slope of the surface, characterizing the rate of the change, is particularly steep for high values of the PDO index. Both the coldest and warmest winters in the Great Lakes occurred when the PDO index was $>1$. The sign of the relationship between the WSI and PDO depends on the range of the N3.4 index. For the range of strong El Niño events, the higher the PDO index, the milder the winter in the Great Lakes. The opposite is true for the range of moderate El Niño events. We hypothesize that the genuine effect of the PDO exhibits itself through an amplification of the ridge-trough system over North America during the warm phase of the oscillation. The effect of strong El Niño events, however, overcomes the effect of the PDO, which results in the non-PNA distribution pattern of winter temperature anomalies shown in Fig. 5a.

A more detailed analysis of the reaction of the Aleutian Low to ENSO and PDO also reveals substantial differences. Table 1 shows central pressure and geographical position of mean winter Aleutian Low for the entire set of data (1901-2000) and 2 subsets characterizing strong El Niño events and warm PDO winters when the El Niño effect is eliminated. The first subset contains 19 winters of strong El Niño events (N3.4 > 1.1). To obtain the second subset, we arranged the winters according to the PDO index and took 19 winters with the highest PDO indices that are not coincident with strong El Niño winters in the first subset. The winters in these 2 subsets are: 
Table 1. Mean values of the parameters of the Aleutian Low for the entire period of 1901-2000 and subsets of strong El Niño and warm PDO winters. LTM: long-term mean

\begin{tabular}{|lrcc}
\hline Parameter & LTM & $\begin{array}{c}\text { Strong } \\
\text { El Niño }\end{array}$ & $\begin{array}{c}\text { Warm } \\
\text { PDO }\end{array}$ \\
\hline Pressure & 997.8 & $994.3^{\mathrm{a}}$ & 995.7 \\
Latitude $\left({ }^{\circ} \mathrm{N}\right)$ & 51.4 & $52.6^{\mathrm{b}}$ & $50.6^{\mathrm{b}}$ \\
Longitude $\left({ }^{\circ} \mathrm{W}\right)$ & 179.0 & $168.9^{\mathrm{ab}}$ & $179.6^{\mathrm{b}}$
\end{tabular}

${ }^{a}$ Difference between mean values for strong El Niño or warm PDO winters and long-term mean are significant at $\mathrm{p}(2$-tail $)<0.05$

${ }^{\mathrm{b}}$ Difference between mean values for strong El Niño and warm PDO winters are significant at $\mathrm{p}(2$-tail $)<0.05$

- strong El Niño events: 1903, 1906, 1912, 1919, 1926, 1931, 1940, 1941, 1942, 1958, 1966, 1969, 1973, 1983, 1987, 1988, 1992, 1995, and 1998;

- warm PDO winters: 1901, 1902, 1908, 1909, 1927, 1928, 1929, 1935, 1936, 1939, 1961, 1970, 1977, 1981, 1982, 1984, 1985, 1986, and 1994.

Both subsets are characterized by a deeper than normal Aleutian Low. The difference is that during warm PDO winters the Aleutian Low remains near its longterm position, whereas during strong El Niño winters it moves northeastward to the Gulf of Alaska. A common perception of a southeastward excursion of the Aleutian Low as a reaction to El Niño events stems from analyses of SLP composites for El Niño and La Niña winters and their differences (e.g. see Niebauer 1998). A negative anomaly center on a typical El Niño minus La Niña composite map is located to the southeast of the normal position of the Aleutian Low. This is not, however, a shift of the center of the Aleutian Low, but rather an indication that over the eastern North Pacific cyclones move at more southern latitudes and farther eastward before they turn north to the Gulf of Alaska during El Niño winters (Chang et al. 2002)

Changes in the geographical position of the Aleutian Low appear to have a more profound effect on winter climate in the Pacific/North American sector than just changes in its strength. Niebauer (1998) has examined the variability in the Bering Sea ice cover as affected by a regime shift in the North Pacific in the late 1970s. One of many manifestations of this shift was a discontinuity of a longestablished relationship between ENSO and Bering Sea ice cover. This relationship is deemed to operate through changes in the position of the Aleutian Low. Before the regime shift, below-normal ice cover was typically associated with El Niño conditions, which caused the Aleutian Low to move eastward of normal, carrying warm Pacific air over the Bering Sea. Conversely, above-normal ice cover was associated with La Niña conditions, which caused the Aleutian Low to move westward, allowing higher pressure to move over the Bering Sea. Since the regime shift, during El Niño events the Aleutian Low has been moving even farther east, causing winds to blow from the east and north off Alaska and resulting in above-normal ice levels in the Bering Sea.

The eastward shift of the Aleutian Low during El Niño events reflects a profound change in the structure of tropospheric long waves in the Northern Hemisphere extratropics. Fig. 8a shows meridional wind anomalies at the $700 \mathrm{hPa}$ level for strong El Niño events since 1950. For comparison we also calculated wind anomalies for warm PDO winters without strong El Niño events (Fig. 8b). Those winters were chosen using the same procedure we used to calculate the characteristics of the Aleutian Low. Since that dataset contained just 9 such winters for the second half of the 20th century, we added 1 more winter (1996) to make the samples equal.

Winters of strong El Niño events (Fig. 8a) are characterized by northerly winds over the east central North Pacific (from the dateline to about $140^{\circ} \mathrm{W}$ ) associated with an upper atmospheric trough, and strong 
a) Strong El Niño events

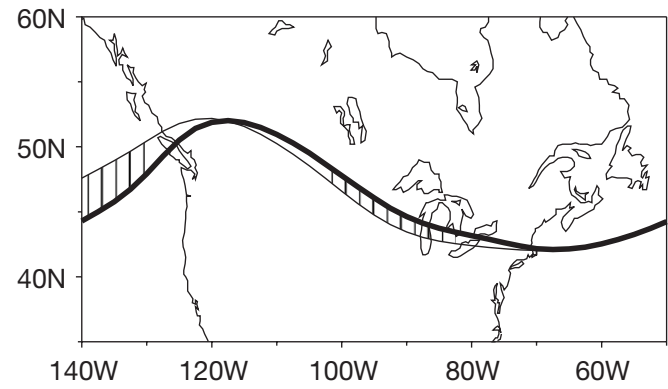

1958

1966

1969

1973

1983

1987

1988

1992

1995

1998

b) PDO w/o strong El Niño events

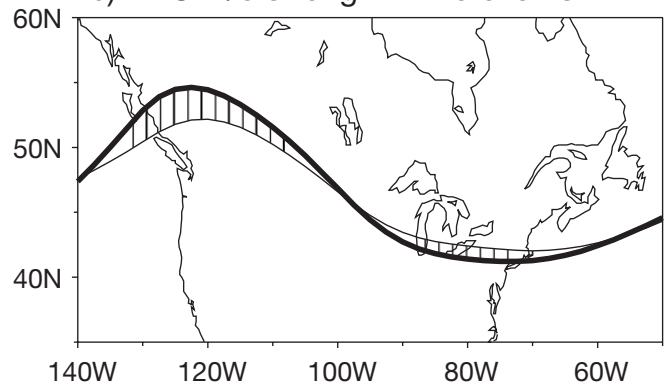

1961

1970

1977

1981

1982

1984

1985

1986

1994

1996

c) Moderate El Niño events

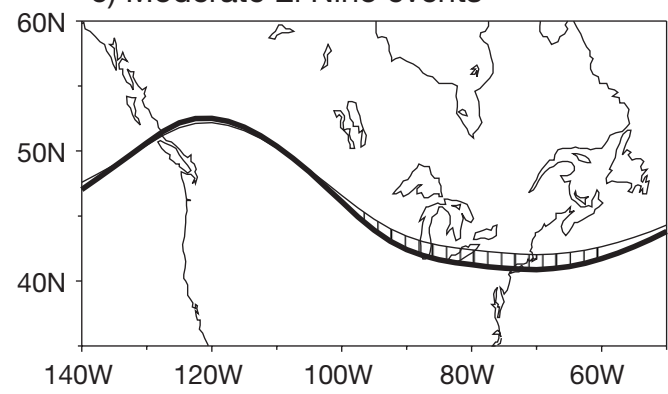

1952

1954

1959

1964

1970

1977

1978

1980

1991

1993

Fig. 9. Mean winter (DJF) position of the 2925 contour at the $700 \mathrm{hPa}$ surface for (a) 10 winters of strong El Niño events, (b) 10 winters of strong warm PDO phase that do not coincide with strong El Niño event, and (c) 10 winters of moderate El Niño events. Thin line: mean position of the 2925 contour for 1949-2000. Vertical lines: significant (at the 95\% level) deviations from the mean position

southerly winds along the ridge over the west coast of North America. Strong gradients of wind speed along $140^{\circ} \mathrm{W}$ are an indication of enhanced cyclonic activity in this region. Airflow over North America has a pronounced southerly component almost all over the continent except its eastern seaboard and the southern tier US.

During warm PDO winters (Fig. 8b) the structure of long waves is much more symmetric than during El Niño winters, with an approximately equal distance between the areas of northerly and southerly winds. This is a classical PNA circulation pattern, with anomalous southerly winds over the eastern North Pacific, northerly wind over much of North America, and again southerly wind over the eastern North Atlantic. A comparison of Fig. 8a and b shows that the only areas in North America where one can expect a similar temperature response to strong warm ENSO and PDO events is a narrow strip along the western seaboard and the southern tier US. Everywhere else the direction of anomalous meridional wind component, and hence temperature anomalies, is opposite for these 2 cases.

The significance of the difference between the effects of ENSO and PDO on the mid-tropospheric circulation over North America is emphasized in Fig. 9. During strong El Niño events (Fig. 9a), the upper atmospheric ridge over the Rockies is near its normal position. The upper atmospheric trough over the eastern half of the continent, however, is not developed, with the maximum northward deviation from normal in the Great Lakes area. As a result, winters in this area are significantly milder than normal. In the absence of strong El Niño events, strong warm PDO winters are associated with an amplified ridge-trough system over North America (Fig. 9b), increased advection of cold air along the western periphery of the trough, and, hence, colder than normal winters in the Great Lakes. The response of the ridge-trough system to moderate El Niño events (Fig. 9c) also features a deeper than normal eastern trough. A comparison of Fig. $9 \mathrm{~b}$ and c suggests that the PDO and moderate El Niño events have a similar effect over the eastern US, which may explain a significantly strong negative correlation between the PDO index and WSI for a range of moderate El Niño events (Fig. 4c). The amount of data available for this study, however, does not allow for a complete separation of the effects of PDO and moderate El Niño events. In fact, 2 years (1970 and 1977) went to both the PDO and moderate El Niño data sets. One of these years (1977) is characterized by an extremely amplified ridge-trough system over North America. Removing this year from the PDO set did not change the configuration of the $2925 \mathrm{~m}$ contour in Fig. $9 \mathrm{~b}$ and only slightly changed the significance of the western ridge. The eastern trough, however, was affected to a larger degree: its significance level was reduced to about $80 \%$.

\section{SUMMARY}

Our analysis has shown that the relationship between ENSO and severity of winters in the Great Lakes is highly nonlinear. Strong El Niño events are associated with warmth in the Great Lakes region, and the stronger the event, the milder the winter. For moderate El Niño events, the correlation between the N3.4 index and North American temperature represents a dipole pattern similar to that for the PNA teleconnec- 
tion: there is a center of positive SAT correlations in the NW part of North America and a center of negative SAT correlations in the SE, with the Great Lakes being between these 2 centers.

The ENSO-WSI relationship can be modulated by decadal climatic variability in the North Pacific. The correlation between ENSO and WSI is weak during cold PDO phases but significantly stronger during warm PDO phases. This can be explained through an increase in frequency of strong El Niño events during warm phases of the PDO.

The effect of PDO on the distribution of SAT anomalies over North America is more symmetric relative to the phase of PDO than that of ENSO. During both warm and cold phases of the PDO, the correlation pattern resembles the one characteristic of the PNA type of circulation, although the absolute values of the correlation coefficients are higher for cold phases of PDO. The PDO-WSI correlation becomes significantly negative for a subset of PDO winters with moderate El Niño events. These events (unlike strong El Niño events) seem to favor a deeper than normal upper atmospheric trough over eastern North America, and thus act in synchrony with PDO itself. In this situation, with the increase in the PDO index, the trough deepens and cold air outbreaks to the Great Lakes region become more frequent.

Strong El Niño events and warm phases of the PDO are both associated with a stronger than normal Aleutian Low. The difference between the effects of these 2 oscillations is due to the geographic position of the Aleutian Low. During strong El Niño events, the Aleutian Low shifts eastward, to the Gulf of Alaska, while during warm PDO phases (not coincident with strong El Niño events!), the Aleutian Low remains near its normal position near the dateline. This eastward shift of the Aleutian Low is a manifestation of the phase shift of the tropospheric planetary waves that redirects the advection of cold and warm air. As a result, winters of strong El Niño events are characterized by an anomalous southerly flow over much of North America, particularly over the western and central regions. In contrast, in the absence of strong El Niño events, warm phases of PDO are conducive to the type of atmospheric circulation with predominantly northerly flow over the continent.

The nonlinear response of North American atmospheric circulation and temperature patterns to the combined ENSO-PDO forcing described in this paper can also explain the decadal variability in severity of winters over the Great Lakes in recent decades. After the shift in the Pacific climate that occurred in 1977, the first phase of a new warm PDO regime until 1982 coincided with warmer-than-normal background temperature conditions in the tropical Pacific, but with no major El Niño events. As we saw above, this situation is conducive to an amplification of the ridge/trough system over North America that is responsible for a series of very cold winters in the Great Lakes. Beginning with the winter of 1983, El Niño events became stronger and more frequent. The effect of these strong El Niño events, which appears to overcome that of the $\mathrm{PDO}$, is the likely cause of abnormally mild winters in the Great Lakes region.

Acknowledgements. We thank Z. Y. Yin (Yin 1994) for providing reconstructed PNA index values and the anonymous reviewers for their useful comments. This is GLERL Contribution No. 1264

\section{LITERATURE CITED}

Angell JK, Korshover J (1984) Some long-term relations between equatorial sea-surface temperature, the four centers of action and $700 \mathrm{mb}$ flow. J Climatol Appl Meteorol 23:1326-1332

Assel RA (1998) The 1997 ENSO event and implication for North American Laurentian Great Lakes winter severity and ice cover. Geophys Res Lett 25:1031-1033

Assel RA, Rodionov S (1998) Atmospheric teleconnections for annual maximum ice cover on the Laurentian Great Lakes. Int J Climatol 18:425-442

Assel RA, Janowiak J, Boyce D, Young S (1996) Comparison of 1994 Great Lakes winter weather and ice conditions with previous years. Bull Am Meteorol Soc 77:71-88

Assel RA, Janowiak J, Boyce D, O'Connors C, Quinn FH, Norton DC (2000) Laurentian Great Lakes ice and weather conditions for the 1998 El Niño winter. Bull Am Meteorol Soc 81:703-718

Barlow M, Nigam S, Berbery EH (2001) ENSO, Pacific decadal variability, and U.S. summertime precipitation, drought, and stream flow. J Clim 14:2105-2128

Biondi F, Gershunov A, Cayan DR (2001) North Pacific decadal climate variability since 1661. J Clim 14:5-10

Bitz CC, Battisti DS (1999) Interannual to decadal variability in climate and glacier mass balance in Washington, Western Canada, and Alaska. J Clim 12:3181-3196

Bjerknes J (1969) Atmospheric teleconnections from the equatorial Pacific. Mon Weather Rev 97:163-172

Bond NA, Harrison DE (2000) The Pacific Decadal Oscillation, air-sea interaction and central north Pacific winter atmospheric regimes. Geophys Res Lett 27:731-734

Bunkers M, Miller JR Jr, DeGaetano AT (1996) An examination of El Niño-La Niña-related precipitation and temperature anomalies across the Northern Plains. J Clim 9: $147-160$

Chang EKM, Lee S, Swanson KL (2002) Storm track dynamics. J Clim 15:2163-2183

Cohen J, Cohen P (1983) Applied multiple regression/correlation analysis for the behavioral sciences. Erlbaum, Hillsdale, NJ

Deser C, Blackmon ML (1995) On the relationship between tropical and North Pacific sea surface temperature variations. J Clim 8:1677-1680

Ebbesmeyer CC, Cayan DR, McClain DR, Nichols FH, Peterson DH, Redmond KT (1991) 1976 step in Pacific climate: forty environmental changes between 1968-1975 and 1977-1984. In: Betancourt JL, Tharp VL (eds) Proc 7th Ann Pacific Climate (PACLIM) Workshop April 1990. Cal- 
ifornia Department of Water Resources. Interagency Ecological Study Program Tech Rep 26, p 115-126

Gershunov A, Barnett TP (1998a) Interdecadal modulation of ENSO teleconnections. Bull Am Meteorol Soc 79: $2715-2726$

Gershunov A, Barnett TP (1998b) ENSO influence on intraseasonal extreme rainfall and temperature frequencies in the contiguous United States: observations and model results. J Clim 11:1575-1586

Gershunov A, Barnett TP, Cayan DR (1999) North Pacific Interdecadal Oscillation seen as factor in ENSO-related North American climate anomalies. EOS 80:25-36

Gershunov A, Schneider N, Barnett T (2001) Low-frequency modulation of the ENSO-Indian monsoon rainfall relationship: signal or noise? J Clim 14:2486-2492

Giese BS, Carton JA (1999) Interannual and decadal variability in the tropical and midlatitude Pacific Ocean. J Clim 12:3402-3418

Graham NE (1994) Decadal-scale climate variability in the tropical and North Pacific during the 1970s and 1980s: observations and model results. Clim Dyn 10:135-162

Graham NE, Barnett TP (1995) ENSO and ENSO-related predictability. Part II: Northern Hemisphere 700-mb height predictions based on a hybrid coupled ENSO model. J Clim 8:544-549

Halpert MS, Ropelewski CF (1992) Surface temperature patterns associated with the Southern Oscillation. J Clim 5: $577-593$

Hamilton K (1988) A detailed examination of the extratropical response to tropical El Niño/Southern Oscillation events. J Climatol 8:67-86

Hannachi A (2001) Toward a nonlinear identification of the atmospheric response to ENSO. J Clim 14:2138-2149

Hare SR, Mantua NJ (2000) Empirical evidence for North Pacific regime shifts in 1977 and 1989. Prog Oceanogr 47: 103-146

Hoerling MP, Kumar A, Zhong M (1997) El Niño, La Niña, and the nonlinearity of their teleconnections. J Clim 10: 769-1786

Hoerling MP, Kumar A, Xu T (2001) Robustness of the nonlinear climate response to ENSO's extreme phases. J Clim 14:1277-1293

Horel JD, Wallace JM (1981) Planetary-scale atmospheric phenomena associated with the Southern Oscillation. Mon Weather Rev 109:813-829

Jones PD (1994) Hemispheric surface air temperature variations: a reanalysis and an update to 1993. J Clim 7: 1794-1802

Kalnay E and 21 coauthors (1996) The NCEP/NCAR reanalysis 40-year project. Bull Am Meteorol Soc 77:437-471

Kiladis GN, Diaz HF (1989) Global climatic anomalies associated with extremes in the Southern Oscillation. J Clim 2: 1069-1090

Latif M, Barnett TP (1994) Causes of decadal climate variability over the North Pacific and North America. Science 266: 634-637

Latif M, Barnett TP (1996) Decadal climate variability over the North Pacific and North America: dynamics and predictability. J Clim 9:2407-2423

Leathers DJ, Yarnal B, Palecki MA (1991) The Pacific/North American teleconnection pattern and United States climate. Part I: Regional temperature and precipitation associations. J Clim 4:517-528

Livezey RE, Masutani M, Leetmaa A, Rui H, Ji M, Kumar A (1997) Teleconnective response of the Pacific-North American region atmosphere to large central equatorial Pacific SST anomalies. J Clim 10:1787-1820
Mantua NJ, Hare SR, Zhang Y, Wallace JM, Francis RC (1997) A Pacific interdecadal climate oscillation with impacts on salmon production. Bull Am Meteorol Soc 78:1069-1079

McCabe GJ, Dettinger MD (1999) Decadal variations in the strength of ENSO teleconnections with precipitation in the western United States. Int J Climatol 19:1399-1410

McPhaden MJ (1999) Genesis and evolution of the 1997-98 El Niño. Science 283:950-954

Mestas-Nuñez AM, Enfield DB (2001) Eastern equatorial Pacific SST variability: ENSO and Non-ENSO components and their climatic associations. J Clim 14:391-402

Miller AJ, Cayan DR, Barnett TP, Graham NE, Oberhuber JM (1994) The 1976-77 climate shift of the Pacific Ocean. Oceanography 7:21-26

Minobe S (1997) A 50-70 year climatic oscillation over the North Pacific and North America. Geophys Res Lett 24: 683-686

Montroy DL, Richman MB, Lamb PJ (1998) Observed nonlinearities of monthly teleconnections between tropical Pacific sea surface temperature anomalies and central and eastern North American precipitation. J Clim 11: $1812-1835$

Nakamura H, Lin G, Yamagata T (1997) Decadal climate variability in the North Pacific during the recent decades. Bull Am Meteorol Soc 78:2215-2225

Namias J (1959) Recent seasonal interactions between North Pacific waters and the overlying atmosphering circulation. J Geophys Res 64:631-646

Namias J (1963) Large-scale air-sea interactions over the North Pacific from summer 1962 through the subsequent winter. J Geophys Res 68:6171-6186

Namias J (1969) Seasonal interactions between the North Pacific Ocean and the atmosphere during the 1960s. Mon Weather Rev 97:173-192

Namias J (1978) Multiple causes of the North American abnormal winter 1976-77. Mon Weather Rev 106:279-295

Namias J, Yuan X, Cayan DR (1988) Persistence of North Pacific sea surface temperature and atmospheric flow patterns. J Clim 1:682-703

Nicholls N, Gruza GV, Jouzel J, Karl TR, Ogallo LA, Parker DE (1996) Observed climate variability and change. In: Houghton JT, Meira Filho LG, Callander BA, Harris N, Kattenberg A, Maskell K (eds) Climate change 1995 IPCC Second Assessment Report. Cambridge University Press, Cambridge, p 133-192

Niebauer HJ (1998) Variabillity in Bering Sea ice cover as affected by a regime shift in the Pacific in the period 1947-1996. J Geophys Res 103:27717-27737

Nigam S, Barlow M, Berbery EH (1999) Analysis links Pacific decadal variability to drought and streamflow in United States. EOS 80:621-632

Parker DE, Jones PD, Bevan A, Folland CK (1994) Interdecadal changes of surface temperature since the late 19th century. J Geophys Res 99:14373-14399

Parker DE, Folland CK, Jackson M (1995) Marine surface temperature: observed variations and data requirements. Clim Change 31:559-600

Renshaw AC, Rowell DP, Folland CK (1998) Wintertime low-frequency weather variability in the North PacificAmerican sector 1949-93. J Clim 11:1073-1093

Renwick JA, Wallace JM (1996) Relationships between North Pacific wintertime blocking, El Niño, and the PNA pattern. Mon Weather Rev 124:2071-2076

Rodionov SN, Assel RA (2000) Atmospheric teleconnection patterns and severity of winters in the Laurentian Great Lakes basin. Atmosphere-Ocean 38:601-635

Ropelewski CF, Halpert MS (1986) North American precipita- 
tion and temperature patterns assocoated with El Niño Southern Oscillation (ENSO). Mon Weather Rev 114: 2352-2362

Shabbar A, Khandekar M (1996) The impact of El NiñoSouthern Oscillation on the temperature field over Canada. Atmosphere-Ocean 34:401-416

Ting M, Wang H (1997) Summertime U.S. precipitation variability and its relation to Pacific sea surface temperature. J Clim 10:1853-1873

Trenberth KE, Hurrell JW (1994) Decadal atmosphere-ocean variations in the Pacific. Clim Dyn 9:303-319

Trenberth KE, Stepaniak DP (2001) Indices of El Niño evolution. J Clim 14:1697-1701

Venrick EL, McGowan JA, Cayan DA, Hayward TL (1987) Climate and chlorophyll 'a': long-term trends in the central North Pacific Ocean. Science 238:70-72

Wallace JM, Jiang Q (1987) On the observed structure of the interannual variability of the atmosphere/ocean

Editorial responsibility: Andrew Comrie,

Tucson, Arizona, USA climate system. In: Cattle $\mathrm{H}$ (ed) Atmospheric and oceanic variability. Royal Meteorological Society, Bracknell, p 17-43

Wolter K, Timlin MS (1993) Monitoring ENSO in COADS with a seasonally adjusted principal component index. In: Proc 17th Climate Diagnostics Workshop, Norman, OK, NOAA/N MC/CAC, NSSL, Oklahoma, Clim Survey CIMMS and the School of Meteorology, University of Oklahoma, pb93-183895 National Technical Information Service, US Dept of Commerce, Springfield, VA, p 52-57

Yin ZY (1994) Reconstruction of the winter Pacific-North American teleconnection pattern during 1895-1947 and its application in climatological studies. Clim Res 4:79-94

Zhang Y, Wallace JM, Iwasaka N (1996) Is climate variability over the North Pacific a linear response to ENSO? J Clim 9:1468-1478

Zhang Y, Wallace JM, Battisti DS (1997) ENSO-like interdecadal variability: 1900-93. J Clim 10:1004-1020

Submitted: June 17, 2002; Accepted: December 10, 2002

Proofs received from author(s): March 27, 2003 